
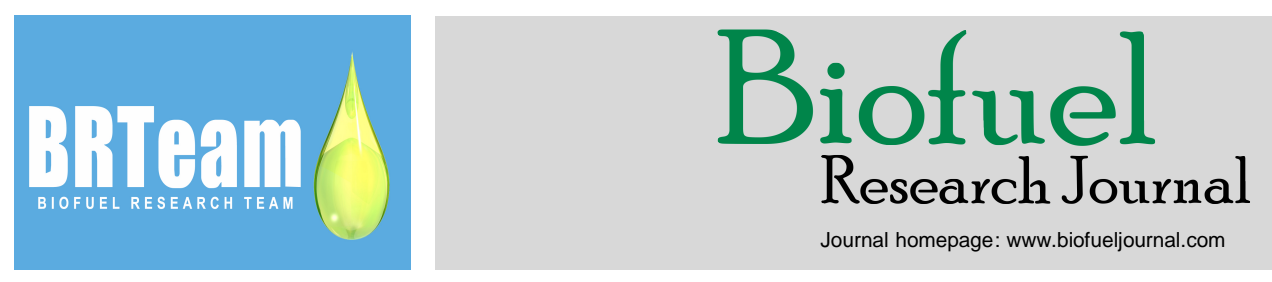

Original Research Paper

\title{
Evaluation of different lignocellulosic biomass pretreatments by phenotypic microarray-based metabolic analysis of fermenting yeast
}

\author{
Stuart Wilkinson, Darren Greetham, Gregory A. Tucker*
}

Brewing Science Section, Division of Food Sciences, The University of Nottingham, Sutton Bonington Campus, Loughborough, Leicestershire LE12 5RD, U.K.

\section{HIGHLIGHTS}

\section{$>$ Efficacy of pre-treatments on different}

lignocellulosic materials tested.

$>$ Phenotypic microarray was used to access

fermentation.

$>$ Alkaline system liberated more sugar but

hydrolysates not as fermentable.

$>$ Acid system had best fermentability.

$>$ Acetic acid and furfural present reduced ethanol

production to $70 \%$ theoretical yield.

\section{GRAPHICAL ABSTRACT}

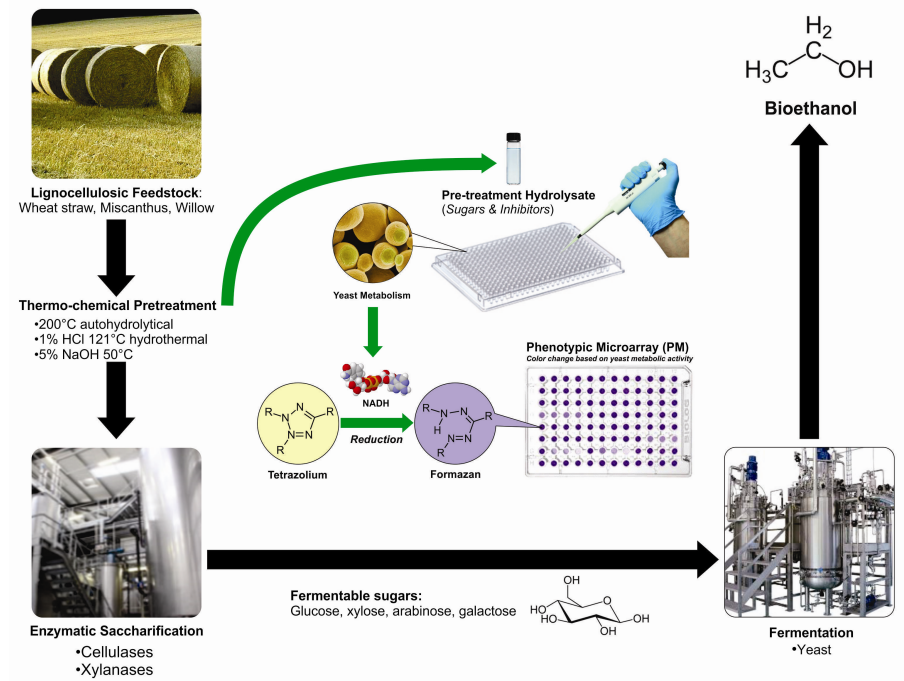

\section{ARTICLE INFO}

\section{Article history:}

Received 30 November 2015

Received in revised form 7 January 2016

Accepted 8 January 2016

Available online 1 March 2016

\section{Keywords:}

Lignocellulosic ethanol

Pre-treatment

Yeast

Metabolic output

Phenotypic microarray

\begin{abstract}
Advanced generation biofuel production from lignocellulosic material (LCM) was investigated. A range of different thermochemical pre-treatments were evaluated with different LCM. The pre-treatments included; alkaline $\left(5 \% \mathrm{NaOH}\right.$ at $\left.50^{\circ} \mathrm{C}\right)$, acid $\left(1 \% \mathrm{H}_{2} \mathrm{SO}_{4}\right.$ at $\left.121^{\circ} \mathrm{C}\right)$ and autohydrolytical methods $\left(200^{\circ} \mathrm{C}\right.$ aqueous based hydrothermal) and were evaluated using samples of miscanthus, wheat-straw and willow. The liberation of sugars, presence of inhibitory compounds, and the degree of enhancement of enzymatic saccharification was accessed. The suitability of the pre-treatment generated hydrolysates (as bioethanol feedstocks for Saccharomyces cerevisiae) was also accessed using a phenotypic microarray that measured yeast metabolic output. The use of the alkaline pre-treatment liberated more glucose and arabinose into both the pre-treatment generated hydrolysate and also the hydrolysate produced after enzymatic hydrolysis (when compared with other pretreatments). However, hydrolysates derived from use of alkaline pre-treatments were shown to be unsuitable as a fermentation medium due to issues with colloidal stability (high viscosity). Use of acid or autohydrolytical pre-treatments liberated high concentrations of monosaccharides regardless of the LCM used and the hydrolysates had good fermentation performance with measurable yeast metabolic output. Acid pre-treated wheat straw hydrolysates were then used as a model system for larger scale fermentations to confirm both the results of the phenotypic microarray and its validity as an effective high-throughput screening tool.
\end{abstract}

() 2016 BRTeam. All rights reserved.

* Corresponding author at: Tel.: +44 (0)115951 6126

E-mail address: gregory.tucker@ nottingham.ac.uk

Please cite this article as: Wilkinson S., Greetham D., Tucker G.A. Evaluation of different lignocellulosic biomass pretreatments by phenotypic microarraybased metabolic analysis of fermenting yeast. Biofuel Research Journal 9 (2016) 357-365. DOI: 10.18331/BRJ2016.3.1.5 


\section{Introduction}

Current environmental, economic, and social concerns regarding the sustainability of use of fossil fuels have led to considerable research into alternative energy resources such as liquid biofuel production from various biomass types (Balat, 2011; Chundawat et al., 2011a). Whilst first generation biofuel production from energy crops such as sugar cane and corn have had some success, concerns over use of potential food sources for the production of transportation fuels has been highlighted (Rathmann et al., 2010). Second generation biofuel production has been developed to minimise this issue through the use of lignocellulosic biomass (utilising the structural polysaccharide components found within the cell wall material), as this material cannot be directly used for human food production (Carvalheiro et al., 2008; Chundawat et al., 2011a).

However, there are considerable technical difficulties to be overcome in order to utilise lignocellulosic feedstocks due to their recalcitrant nature which resists biotic degradation (such as via enzymatic hydrolysis routes). As a consequence of this recalcitrance, the production of second generation biofuels from lignocellulosic biomass (such as wheat straw, willow, and miscanthus) normally requires chemical or thermal pre-treatment prior to enzymatic saccharification in order to boost fermentable sugar yields (Binod et al., 2012; Galbe, 2012). The aim of the pre-treatment is to improve enzymatic access to the cellulosic component within the lignocellulosic matrix through solubilisation or fractionation of various components. Different pre-treatments target different components with autohydrolytical (entirely aqueous based hydrothermal techniques) and acid catalysed hydrothermal pre-treatments primarily targeting hemicellulose removal whilst alkaline (caustic) reagents primarily targets lignin removal (Girio et al., 2010; Banerjee et al., 2011). Pre-treatment has been highlighted as the most energy intensive stage of the second generation biofuel process, and optimising protocols in terms of minimising chemical and energy inputs is crucial for any potential large scale production (Yang and Wyman, 2008).

In addition to energy efficiency, the use of excessive pre-treatment reaction conditions results in the formation of compounds which act as inhibitors to downstream processes including enzymatic saccharification and fermentations (Palmqvist et al., 1998; Chheda et al., 2007; Allen et al., 2010). These compounds are often the result of thermal or chemical degradation of liberated sugars (to furan based inhibitors) or lignin (to phenolic/hydroxycinnamic acid based inhibitors). Hydrolysates are generated directly from the pre-treatment step (the liquid fractions) and they can contain significant concentrations of these compounds. This can present significant problems (such as long yeast lag phases, poor attenuation, and sub-optimal ethanol yields) for any fermentations conducted using these hydrolysates. These hydrolysates can contain a significant quantity of supplementary fermentable sugars (in addition to those liberated after enzymatic saccharification). As such, their use is crucial for maximising the use of lignocellulosic material (LCM) as a biofuel substrate. Consequently, the assessment of the fermentation performance of these hydrolysates is a key factor in identifying issues which may reduce the efficiency of any proposed biofuel production systems using LCM. Additionally, identifying pretreatment systems that generate excessive quantities of inhibitors is a key factor in the formulation of effective advanced generation biofuel production processes.

Wheat-straw (Triticum aestivum L.) is a by-product from wheat production and was chosen due to its status as the largest biomass feedstock in the Europe (Saha and Cotta, 2006). Miscanthus $\times$ giganteus or miscanthus is an Asian perennial rhizomatous grass and is potentially a dedicated energy crop (Bauen et al., 2010). This was chosen due to its current major use as a fuel for heat generation in power stations (DEFRA, 2007) and also as a representative of herbaceous, perennial biomass (McKendry, 2002). Perennials are often considered superior to annuals in terms of their lower pesticide and fertiliser requirements and their superior usage of nutrients (Jorgensen, 2011). Short rotation coppice (SRC) willow was also chosen as another candidate due to its high growth yields and again low fertiliser requirements as with miscanthus (Ray, 2012) and as a model for the woody biomass type (Sticklen, 2008).

Three different pre-treatments were selected and applied on commonly available LCMs which have all previously been highlighted as potential energy crops in the UK (Glithero, 2013a; Glithero et al., 2013b). The pretreatments were all chosen as effective for LCM and consisted of an acid hydrothermal system; $1 \% \mathrm{H}_{2} \mathrm{SO}_{4}$ at $121^{\circ} \mathrm{C}$ (Wilkinson et al., 2014a), an alkaline system; $5 \% \mathrm{NaOH}$ at $50^{\circ} \mathrm{C}$ (Wilkinson et al., 2014b), and finally an autohydrolytical system; $200^{\circ} \mathrm{C}$ aqueous based (Wilkinson et al., 2015). Use of sodium hydroxide as an alkali pre-treatment has been well established and successful, as alkali does not cause sugar degradation (Chang and Holtzapple, 2000). Dilute acid pre-treatments reduce hemicellulose to its monomeric sugars making cellulose more accessible (Nguyen et al., 2000) and use of autohydrolytical methods causes hemicellulose to become solubilised making the cellulose more accessible (Chandra et al., 2007)

This paper evaluated the efficacy of different pre-treatment protocols on various LCMs. Efficacy was determined in terms of differences in liberated sugar yield (both directly into the pre-treatment generated hydrolysate and also post cellulolytic enzymatic saccharification), the degree of formation of metabolically inhibitory compounds, and the subsequent fermentation performance of the pre-treatment generated hydrolysates. The fermentation performance was then assessed using a phenotypic microarray (PM) as a novel, rapid screening tool that has previously been used to measure yeast metabolic output (Greetham, 2014 Wimalasena et al., 2014). To the author's knowledge, very few studies have been published using the PM for screening the fermentability of different biofuel feedstocks. The PM results were then confirmed using larger scale fermentations using wheat straw (with acid pre-treatment) as a model system. This validated the use of the PM as a novel, highthroughput screening tool for identifying issues with fermentability of biofuel feedstocks.

\section{Materials and methods}

\subsection{Yeast strain and growth conditions}

Saccharomyces cerevisiae NCYC 2592 (www.ncyc.co.uk) was maintained on agar containing $10 \mathrm{~g} / \mathrm{L}$ yeast extract, $20 \mathrm{~g} / \mathrm{L}$ peptone, 20 $\mathrm{g} / \mathrm{L}$ glucose, and $20 \mathrm{~g} / \mathrm{L}$ agar (YPD agar) and grown in $10 \mathrm{~g} / \mathrm{L}$ yeast extract, $20 \mathrm{~g} / \mathrm{L}$ peptone, and $20 \mathrm{~g} / \mathrm{L}$ glucose (YPD) in an orbital shaker $(180 \mathrm{rpm})$ at $30^{\circ} \mathrm{C}$ under aerobic conditions.

\subsection{Raw materials and inhibitors}

Inhibitory chemicals such as acetic, formic, $p$-coumaric, and ferulic acids, furfural, 5-hydroxymethylfurfural (HMF), syringaldehyde, and vanillin were all supplied by Sigma (Dorset, UK). Other chemicals were standard laboratory reagents. Wheat straw was harvested at the University of Nottingham. Willow and miscanthus were harvested at Rothamsted (BBSRC funded) and details of the harvest have been published previously (Ray, 2012). Willow and miscanthus were harvested as part of field trials conducted under the BBSRC's BSBEC renewable initiative with site permission from the Lawes Trust; grid coordinates $51.8168^{\circ} \mathrm{N}$ and $0.3798^{\circ} \mathrm{W}$.

\subsection{Pre-treatments of LCM (wheat straw, miscanthus, and willow)}

Acid catalysed hydrothermal pre-treatments were conducted using the protocol described previously (Wilkinson et al., 2014a). Biomass $(50 \mathrm{~g}$ dry weight) was added to $500 \mathrm{~mL} 1 \% \mathrm{H}_{2} \mathrm{SO}_{4}(\mathrm{w} / \mathrm{v})$ in a screw-capped glass bottle $(1 \mathrm{~L})$ to give the required solids-loading $(10 \% \mathrm{w} / \mathrm{v})$. This was then heated at $121^{\circ} \mathrm{C}$ for $30 \mathrm{~min}$ using a $40 \mathrm{~L}$ bench top autoclave (Priorclave, Tactrol 2, RSC/E, UK). Alkaline pre-treatments were conducted as described previously (Wilkinson et al., 2014b). $500 \mathrm{~mL}$ borosilicate glass bottles with the appropriate amount of biomass $(25 \mathrm{~g})$ and caustic reagent $(5 \% \mathrm{NaOH} w / \mathrm{w})$ required to achieve the $10 \%(\mathrm{w} / \mathrm{v})$ solids loading were incubated at $50^{\circ} \mathrm{C}$ for $12 \mathrm{~h}$ in a GD100 water bath (Grant, UK). Microwave-assisted autohydrolytical pre-treatment was conducted using the described protocol (Wilkinson et al., 2015c). A Monowave 300 microwave synthesis reactor (Anton Paar Gmbh, Gratz, Austria) was used. Glass $\mathrm{G} 30(30 \mathrm{~mL})$ microwave reaction vessels (Anton Paar Gmbh, Gratz, Austria) with the appropriate amount of biomass $(2.0$ $\mathrm{g})$ and water $(20 \mathrm{~mL})$ required to achieve the $10 \%(\mathrm{w} / \mathrm{v})$ solids loading were heated at $200^{\circ} \mathrm{C}$ for $5 \mathrm{~min}$.

After pre-treatment, samples were centrifuged at $3500 \times \mathrm{g}$ for $10 \mathrm{~min}$ and the supernatant was removed for analysis of sugars and known 
inhibitory compounds. The residual biomass was then re-suspended in reverse osmosis (RO) water $(20 \mathrm{~mL})$. The three different re-suspended pre-treatment samples all had widely different $\mathrm{pH}$ values: $\mathrm{pH} 14( \pm 0.3)$ for the alkaline sample, pH $2( \pm 0.3)$ for the acid sample, and $\mathrm{pH} 4( \pm 0.3)$ for the autohydrolytical sample. As such, all were adjusted to $\mathrm{pH} 5.0( \pm 0.1)$ with either glacial acetic acid or $40 \% \mathrm{NaOH}(\mathrm{w} / \mathrm{v})$ and then exhaustively washed with $\mathrm{RO}$ water (by repeated re-suspension and centrifugation at $3500 \times \mathrm{g}$ for $10 \mathrm{~min}$, discarding the supernatant each time). The remaining residues were then oven-dried overnight at $60^{\circ} \mathrm{C}$ prior to enzymatic saccharification. All experiments were conducted in triplicate.

\subsection{Enzymatic saccharification of pre-treated residues}

All enzyme digestions of pre-treatment residues were conducted using $24 \mathrm{~h}$ incubation periods at $50^{\circ} \mathrm{C}$ with agitation at $150 \mathrm{rpm}$ (MaxQ 4358 shaking incubator, Thermo Scientific, UK). The assessment of the efficacy of different pre-treatment processes was conducted using a low solids-loading protocol $(0.5 \% \mathrm{w} / \mathrm{v})$ with lyophilised Celluclast ${ }^{\circledR}$ cellulase from Trichoderma reesei (ATTC 26921, Sigma-Aldrich, UK) using an excess of enzyme (50 FPU/g biomass) to determine the maximum sugar concentration obtainable. Pretreated residue $(200 \mathrm{mg})$ was mixed with $40 \mathrm{~mL}$ of a $1 \mathrm{~g} / \mathrm{L}$ Celluclast ${ }^{\circledR}$ solution in $50 \mathrm{mM}$ sodium citrate buffer (adjusted to $\mathrm{pH} 4.8$ via glacial acetic acid) and incubated at $50^{\circ} \mathrm{C}$ for $24 \mathrm{~h}$. Following the incubation period, the samples were centrifuged at $3500 \times \mathrm{g}$ for $10 \mathrm{~min}$ and the supernatant was sampled for quantification of sugars via ion chromatography (IC). The FPU was determined according to the method described by Ghose (1987). All experiments were conducted in triplicate.

\subsection{Quantification of total monosaccharide content of pre-treated residues}

Total glucose, xylose, and arabinose concentrations were quantified from total sugar analysis using IC after complete acid hydrolysis of the pre-treated residues using the protocol described previously (Wilkinson et al., 2014b). Dried biomass $(30 \mathrm{mg})$ was weighed into a heat resistant Pyrex reaction vessel $(50 \mathrm{~mL})$. To each tube was added $1 \mathrm{~mL}$ of $12 \mathrm{M} \mathrm{H}_{2} \mathrm{SO}_{4}$ and the contents were incubated at $37^{\circ} \mathrm{C}$ in a water bath for $1 \mathrm{~h}$. Water $(11 \mathrm{~mL})$ was added to dilute the acid concentration to $1 \mathrm{M}$ and the contents were further incubated at $100^{\circ} \mathrm{C}$ for $2 \mathrm{~h}$. The resulting solutions were then syringe-filtered (GF/C $25 \mathrm{~mm}$ filter diameter/1.2 $\mu \mathrm{m}$ pore size, Whatman, USA) and the concentration of monosaccharides was quantified by IC as described in the Section 2.8 .

\subsection{High performance chromatography (HPLC) and IC}

\subsubsection{Quantification of weak acid based inhibitors present in the pre- treatment generated hydrolysates}

HPLC (utilising an AS-2055 Intelligent Auto-sampler and a PU-1580 Intelligent HPLC Pump; Jasco, Japan) was used for the analysis of acetic and formic acid. An aliquot $(20 \mu \mathrm{L})$ of the hydrolysate (the liquid fraction generated directly from the pre-treatment step) was injected onto a $250 \times 4.6$ $\mathrm{mm}$ Synergi Hydro-RP column (Phenomenex, Macclesfield UK). The compounds were eluted with $20 \mathrm{mM}$ potassium dihydrogen phosphate buffer $(\mathrm{pH} 2.5)$ at a flow rate of $1 \mathrm{~mL} / \mathrm{min}$ and detected at $220 \mathrm{~nm}$ using a Spectro Monitor 3000 UV spectrophotometer (Milton Roy, Stone, UK). The amounts of acetic and formic acid were determined by peak area comparison (Azur software, Jasco, Great Dunmow UK) with authentic standards.

\subsubsection{Quantification of furan and phenolic based inhibitors present in the pre-treatment generated hydrolysates}

Furan and phenolic based inhibitors were quantified using HPLC with UV detection at $280 \mathrm{~nm}$ using the protocol described previously (Wilkinson et al., 2014b).
2.6.3. Quantification of monosaccharides in the pre-treatment generated hydrolysates and the feedstocks produced after enzymatic saccharification of pre-treated LCM

Liberated sugars were quantified via IC using an ICS 3000 system (Dionex, USA) fitted with a CarboPac PA20 column $(150 \mathrm{~mm} \times 3.0 \mathrm{~mm}$ Dionex, USA) with pulsed amperometric electrochemical detection (PAD) using the method described by Wilkinson et al. (2014b).

\subsection{Phenotypic microarray (PM) analysis}

The Biolog OmniLog (Biolog, Hayward, CA, USA) was used as a rapid screening tool to measure the metabolic output of the yeast when cultured in the pre-treatment generated hydrolysates. This was primarily to evaluate the response of the yeast to the inhibitors present in the hydrolysates and to identify any issues with fermentation performance The fermentation performance of the feedstocks generated after enzymatic saccharification was not evaluated. Instead, this study concentrated specifically on the pre-treatment generated hydrolysate. As the biomass had been exhaustively washed after pre-treatment (before the enzymatic saccharification step) the feedstocks subsequently produced would have contained negligible concentrations of inhibitors.

Biolog growth medium was prepared using $0.67 \%(\mathrm{w} / \mathrm{v})$ yeast nitrogen base (YNB) supplemented with $6 \%(\mathrm{w} / \mathrm{v})$ glucose, and $0.2 \mu \mathrm{L}$ of tetrazolium redox dye (dye D; specific for fungi) (Biolog, Hayward, CA, USA). Final volume was made up to $30 \mu \mathrm{L}$ using RO sterile distilled water and aliquoted to individual wells. Microarray analysis experiments on the effects of acetic acid and furfural were set up as above but the amount of RO sterile distilled water added was modified to account for the presence of the inhibitory compounds. Stock solution (1 M) of acetic acid, was prepared using RO water; furfural was prepared as $1 \mathrm{M}$ stock solutions in $100 \%$ ethanol. Hydrolysates were spiked with the appropriate concentrations of glucose to give a $6 \%$ final solution and $0.2 \mu \mathrm{L}$ of dye $\mathrm{D}$ was added. Strains were prepared for inoculation into the PM assay plates as follows. Glycerol stocks stored at $-80^{\circ} \mathrm{C}$ were streaked onto YPD plates and incubated at $30^{\circ} \mathrm{C}$ for approximately $48 \mathrm{~h}$. Two to three colonies from each strain were re-streaked to one section of a fresh YPD plate and incubated overnight at $30^{\circ} \mathrm{C}$. Cells were then inoculated into sterile water in $20 \times 100 \mathrm{~mm}$ test tubes and adjusted to a transmittance of $62 \%\left(\sim 5 \times 10^{6}\right.$ cells $/ \mathrm{mL}$ ) using a Biolog turbidimeter (Biolog, USA). Cell suspensions for the inoculums were prepared by mixing $125 \mu 1$ of the above cells with IFY bufferTM (Biolog, USA) and the final volume was adjusted to $3 \mathrm{~mL}$ using RO sterile distilled water. Next $90 \mu \mathrm{l}$ of the above mix was inoculated into each well in a Biolog 96-well plate. Anaerobic conditions were created using Oxygen absorbing packs (Mitsubish AnaeroPak ${ }^{\mathrm{TM}}$ System, Pack-Anaero, Mitsubishi Gas Chemicals, Tokyo, Japan) with an anaerobic indicator (Oxoid, Basingstoke, UK) and the plates were placed inside PM gas bags (Biolog, USA). The plates were then placed in the OmniLog reader and incubated for $50 \mathrm{~h}$ at $30^{\circ} \mathrm{C}$. The OmniLog reader photographed the PM plates at 15 min intervals, and converted the pixel density in each well to a signal value reflecting cell growth and dye conversion. Dye reduction which reflects metabolic activity of cells was defined here as the redox signal intensity. After completion of the run, the signal data was compiled and exported from the Biolog software using Microsoft ${ }^{\circledR}$ Excel. In all cases, a minimum of three replicate PM assay runs were conducted, and the mean signal values are presented. All experiments were conducted in triplicate.

\subsection{Confirmation of phenotypic microarray results using larger scale fermentations}

Fermentations using pre-treatment generated hydrolysates were conducted in $180 \mathrm{~mL}$ fermentation vessels (FVs). Cryopreserved yeast colonies were streaked onto YPD plates and incubated at $30^{\circ} \mathrm{C}$ for $48 \mathrm{~h}$. These were then transferred to $200 \mathrm{~mL}$ of YPD and grown for $48 \mathrm{~h}$ in a $500 \mathrm{~mL}$ conical flask shaking at $30^{\circ} \mathrm{C}$. Cells were harvested and washed three times with sterile RO water and then re-suspended in $5 \mathrm{~mL}$ of sterile water. Under control conditions, $1.5 \times 10^{7}$ cells $/ \mathrm{mL}$ were inoculated in 
$92.5 \mathrm{~mL}$ of medium containing $4 \%$ glucose, $2 \%$ peptone, $1 \%$ yeast extract with $7.5 \mathrm{~mL}$ RO water. $92.5 \mathrm{~mL}$ hydrolysate was spiked with $7.5 \mathrm{~mL}$ from an $80 \%$ glucose stock to give a final glucose concentration of $6 \%$ and buffered to a starting $\mathrm{pH}$ of 5 using $2 \mathrm{M} \mathrm{NaOH}$. Anaerobic conditions were prepared using a sealed butyl plug (Fisher, Loughborough, UK) and aluminium caps (Fisher Scientific). A hypodermic needle attached with a Bunsen valve was purged through rubber septum to facilitate the release of $\mathrm{CO}_{2}$. All experiments were performed in triplicate and weight loss was measured at each time point. Fermentations were conducted at $30^{\circ} \mathrm{C}$, with orbital shaking at $200 \mathrm{rpm}$. All experiments were conducted in triplicate.

\section{Results and discussion}

Three different pre-treatments were employed on three commonly available LCMs. The LCMs chosen have all previously been highlighted as potential energy crops in the UK (Glithero, 2013a; Glithero et al., 2013b) and this study looked at the efficacy of the pre-treatments in terms of sugars liberated, presence of inhibitory compounds, $\mathrm{pH}$, and yeast fermentation performance.

\subsection{Liberation of sugars from LCM using a range of pre-treatments.}

The assessment of liberation of monomeric sugars from LCM into the hydrolysate (sugars liberated directly into the liquid fraction generated from the pre-treatment) was conducted following three pre-treatments. Hydrothermal pre-treatment (employing $1 \% \mathrm{H}_{2} \mathrm{SO}_{4}$ at $121^{\circ} \mathrm{C}$ for $30 \mathrm{~min}$ ) liberated significantly higher concentrations of xylose, arabinose, and glucose when compared with use of alkaline $\left(5 \% \mathrm{NaOH}\right.$ at $\left.50^{\circ} \mathrm{C}\right)$ or autohydrolytical $\left(200^{\circ} \mathrm{C}\right.$ microwave-assisted) pre-treatment methods regardless of the LCM used (Fig. 1A)

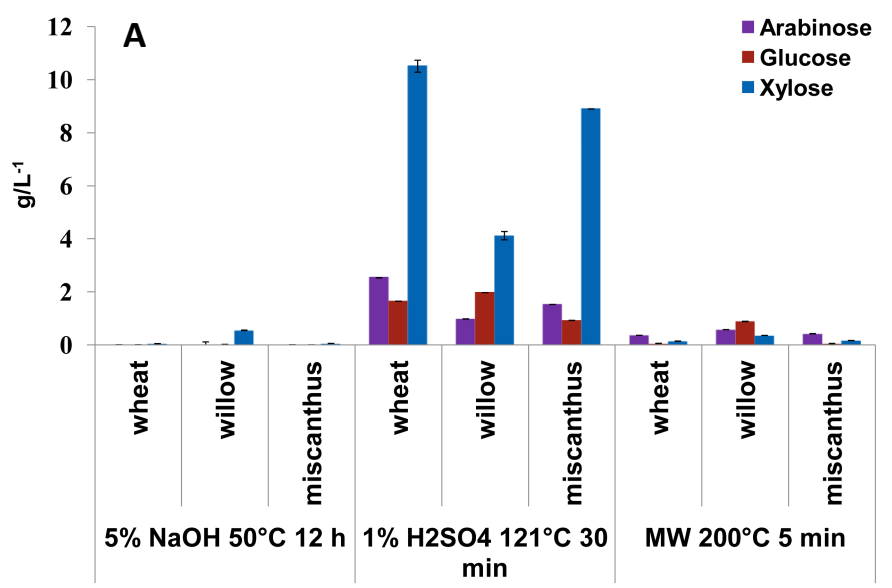

Pre-treatment /plant material was the only pre-treatment to exhibit specific LCM biomass type related variability in the $\%$ theoretical xylose concentrations achieved, with willow and miscanthus liberating $7 \%$ and $33 \%$ more xylose than wheatstraw, respectively. Although containing high concentrations of fermentable glucose, the fermentation performance of the feedstocks generated after enzymatic saccharification was not evaluated.

\subsection{Liberation of acetic acid from the pre-treatment process}

Regardless of the LCM or pre-treatment employed, relatively high concentrations of acetic acid (30-75 mM: Fig. 2A) were present in all samples which would have been high enough to affect yeast growth rates and reduce glucose consumption (Narendranath et al., 2001). In general, use of autohydrolytical pre-treatment liberated lower concentrations of acetic acid (30-35 $\mathrm{mM})$ when compared to the hydrolysates from the same LCM using either the alkaline or acid pre-treatments (61-69 mM and 45$73 \mathrm{mM}$ respectively) (Fig. 2A).

\subsection{Presence of weak acid, furan, and phenolic based inhibitors in the pre-treatment generated hydrolysates}

The concentrations of weak acids (i.e., $p$-coumaric, ferulic, and formic acid), furans (i.e., HMF and furfural) and additional phenolic compounds (i.e., vanillin and syringaldehyde) present in hydrolysates after pretreatment of LCM was measured. Very low concentrations of these compounds were detected in hydrolysates generated using alkaline $(5 \%$ $\mathrm{NaOH}$ at $50^{\circ} \mathrm{C}$ ) pre-treatment with the exception of syringaldehyde in hydrolysates from miscanthus and wheat. Presence of $10 \mathrm{mM}$ syringaldehyde has been observed to reduce ethanol productivity by

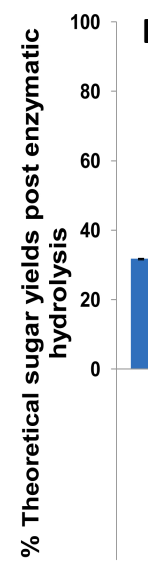

B

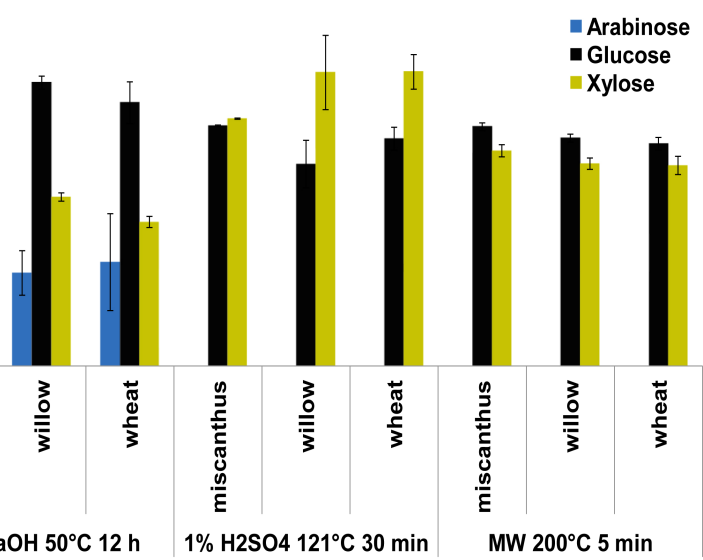

Pre-treatment/plant material

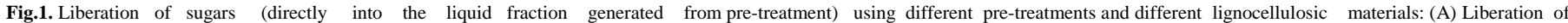

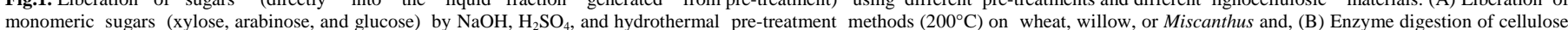

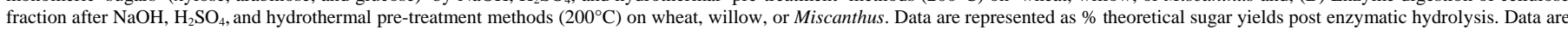
representative of triplicate values with standard deviation shown.

\subsection{Sugar yields from pre-treated biomass after enzymatic saccharification}

Assessment of the sugar levels liberated after enzymatic saccharification from the various pre-treated residues indicated that similar theoretical glucose yields (ca. 65\%) were achieved from all three biomass types using either acid $\left(1 \% \mathrm{H}_{2} \mathrm{SO}_{4}\right.$ at $\left.121^{\circ} \mathrm{C}\right)$ or $200^{\circ} \mathrm{C}$ microwave-assisted autohydrolytical pretreatment protocols. However, use of the alkaline $\left(5 \% \mathrm{NaOH}\right.$ at $\left.50^{\circ} \mathrm{C}\right)$ pretreatment liberated the highest glucose yield (ca. 75\% theoretical) from all LCM biomass types (Fig. 1B). In addition, a significant arabinose concentration was detected only in pre-treatments using the alkaline system (which only equated to ca. 30\% theoretical yield). Similar \% theoretical xylose concentrations were observed from all biomass types using either the acid or autohydrolytical pre-treatment systems. The alkaline pre-treatment approximately $30 \%$ when compared with unstressed controls without the compound present (Taherzadeh and Karimi, 2008). In the present study, 4 $\mathrm{mM}$ syringaldehyde was detected in hydrolysates derived from miscanthus and $2 \mathrm{mM}$ in hydrolysates derived from wheat (Fig. 2B).

3.5. Metabolic profiling of yeast cultured in pre-treatment generated hydrolysates (supplemented with glucose)

The PM was used for the metabolic profiling of the different pretreatment generated hydrolysates (Fig. 3). The hydrolysates were supplemented with glucose to ensure a suitable carbon source was present (to avoid anystarvation-induced effects) and any effects of the presence of the inhibitors could then be accurately determined. The starting $\mathrm{pH}$ of the 


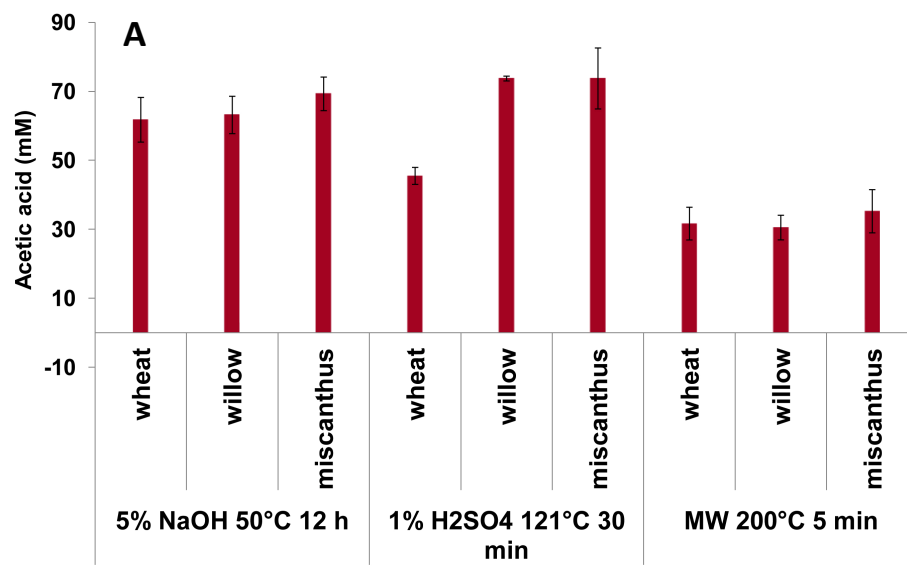

Pre-treatment/plant material

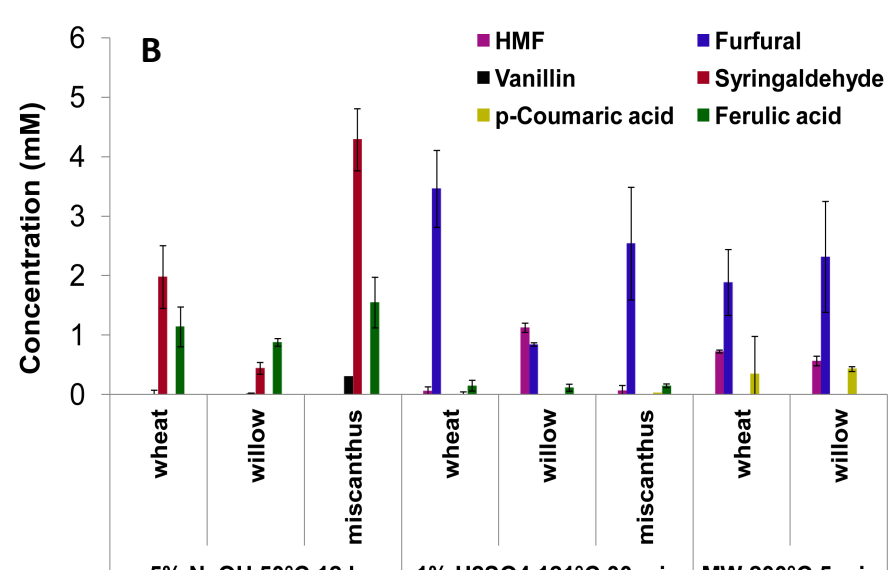

$5 \% \mathrm{NaOH} 50^{\circ} \mathrm{C} 12 \mathrm{~h}$
$1 \% \mathrm{H} 2 \mathrm{SO} 4121^{\circ} \mathrm{C} 30 \mathrm{~min} \quad \mathrm{MW} 200^{\circ} \mathrm{C} 5 \mathrm{~min}$

Pre-treatment/plant material

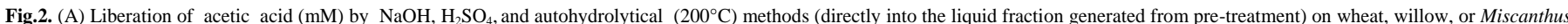

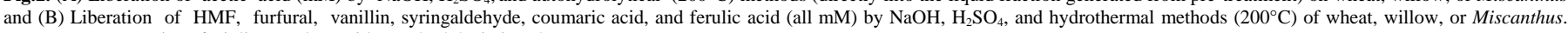
Data are representative of triplicate values with standard deviation shown.

hydrolysates was adjusted to $\mathrm{pH} \mathrm{5,} \mathrm{as} \mathrm{typical} \mathrm{fermentations} \mathrm{start} \mathrm{at} \mathrm{this} \mathrm{pH}$ and then subsequently typically drop to ca. pH 4.1 (Coote and Kirsop, 1976). The $\mathrm{pH}$ adjustment was problematic for the hydrolysates derived from the alkaline pre-treatment system as the $\mathrm{pH}$ (post pre-treatment) was ca. $\mathrm{pH} 14$. As such, the adjustment down to $\mathrm{pH} 5$ resulted in a significant increase viscosity (significant effects on the colloidal stability) which made it subsequently problematic to work with from a practical point. Alternatively, the $\mathrm{pH}$ of acid and autohydrolytical pre-treatment generated hydrolysates was $\mathrm{pH} 2$ and $\mathrm{pH} 6$, respectively, and as such, the $\mathrm{pH}$ adjustment of these hydrolysates did not cause a fundamental change in viscosity or physical properties of the media.
Yeast metabolic output when cultured in hydrolysates derived from the alkaline pre-treatment system was severely reduced when compared to controls containing an identical quantity of glucose but no inhibitors (Fig. 4A). This was possibly due to the buffering that was required to adjust the $\mathrm{pH}$ down to $\mathrm{pH} 5$ rather than the presence of syringaldehyde. There is also the possibility that alkaline pre-treatments generate hydrolysates had reduced nitrogen levels (in particular reduced free amino nitrogen or FAN levels) when compared with other pre-treatments. Overall, yeast metabolic output was shown to be higher when using acid or autohydrolytical pre-treatment derived hydrolysates than those derived from the use of alkaline pre-treatment (Figs. $4 \mathrm{~B}$ and $4 \mathrm{C}$ ). Additionally
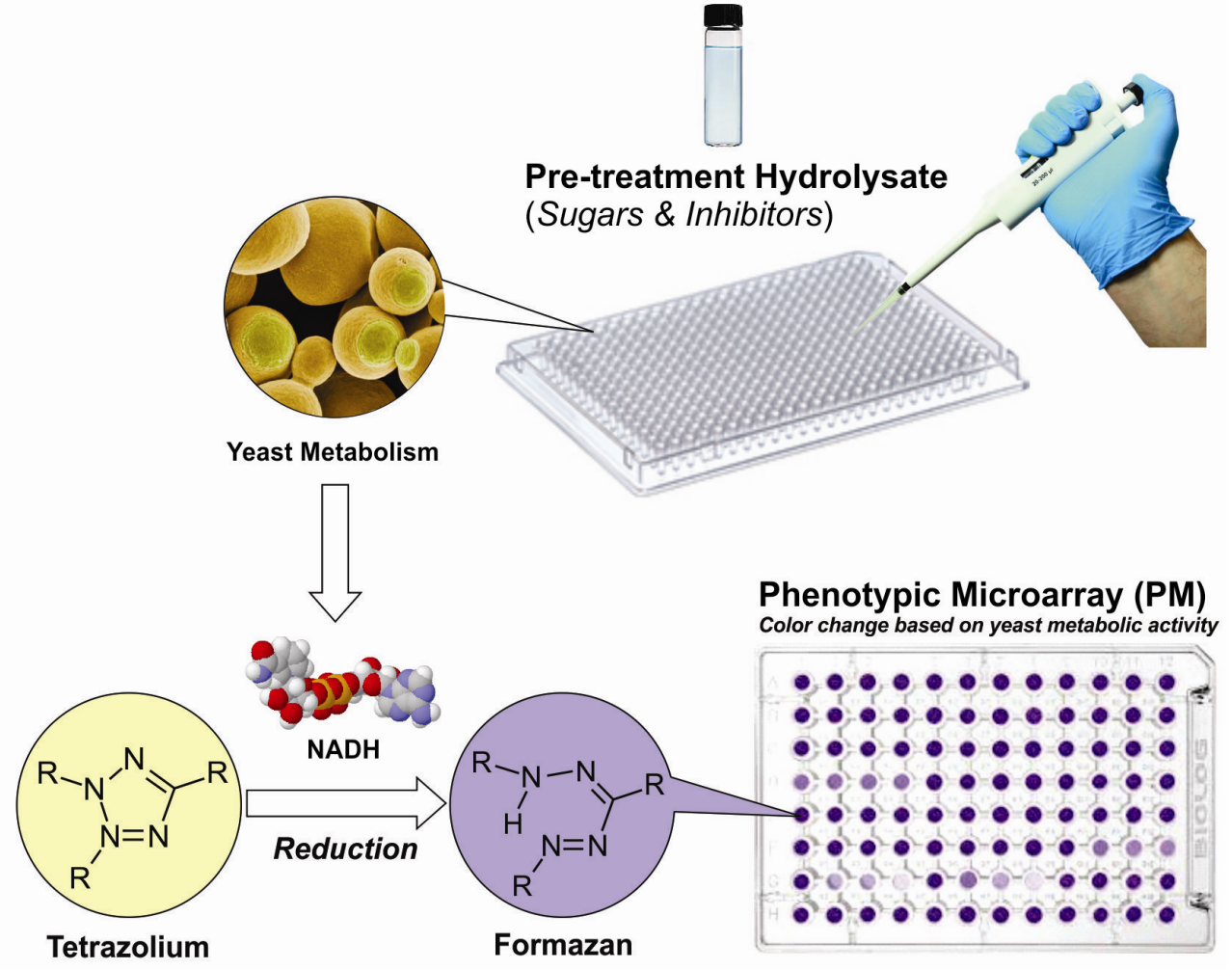

Fig.3. Evaluation of different lignocellulosic biomass pretreatments by phenotypic microarray-based metabolic analysis of fermenting yeast 

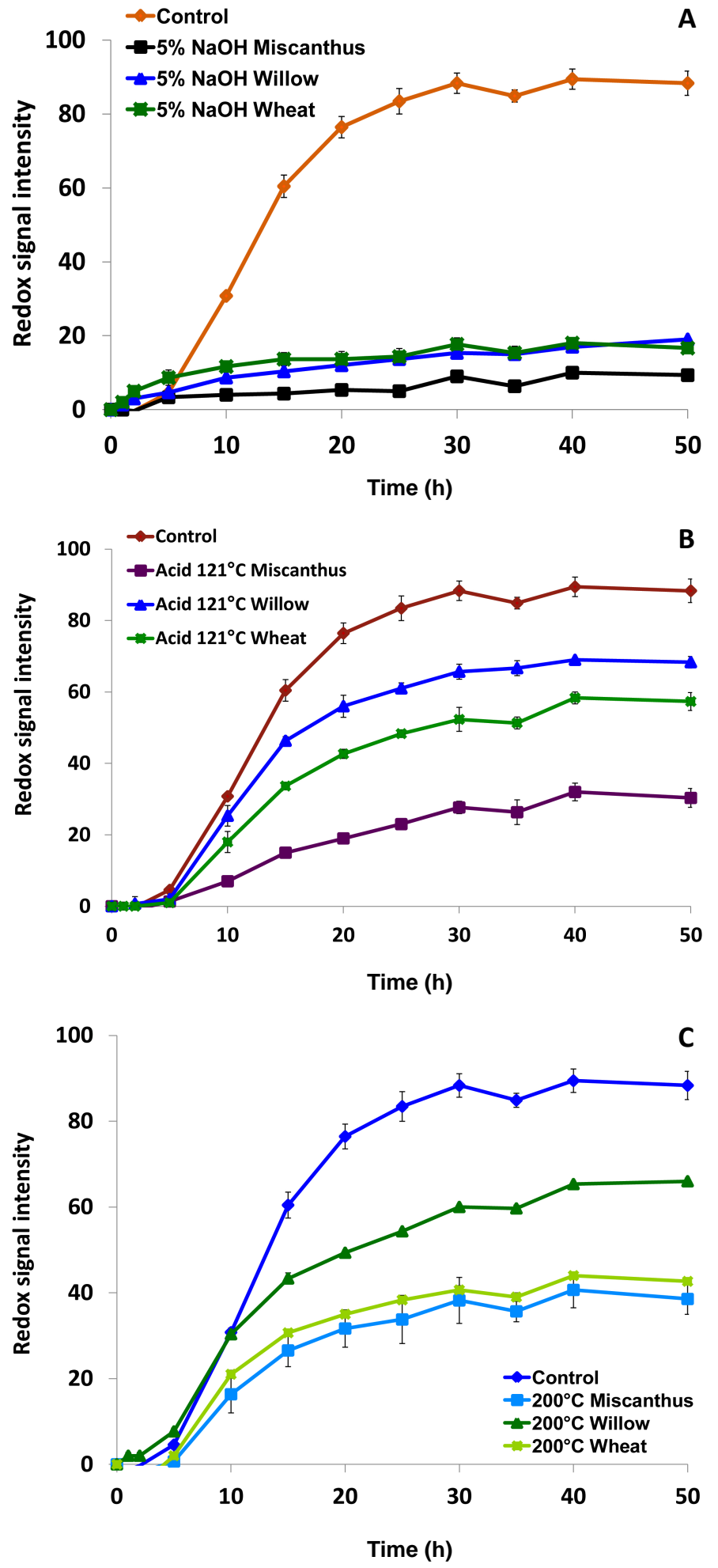

Fig.4. Phenotypic microarray analysis (redox signal intensity) for S. cerevisiae (NCYC 2592) on hydrolysates derived from $\mathrm{NaOH}, \mathrm{H}_{2} \mathrm{SO}_{4}$, and hydrothermal pre-treatment methods $\left(200^{\circ} \mathrm{C}\right)$ on wheat, willow, or Miscanthus. Plates were incubated at $30^{\circ} \mathrm{C}$ and read for $50 \mathrm{~h}$, under anaerobic conditions: (A) Metabolic output (redox signal intensity) for hydrolysates from wheat, willow, and Miscanthus using $\mathrm{NaOH}$ as a pre-treatment method, (B) Metabolic output (redox signal intensity) for hydrolysates from wheat, willow, and Miscanthus using acid hydrolysis as a pre-treatment method, and (C) Metabolic output (redox signal intensity) for hydrolysates from wheat, willow, and Miscanthus using hydrothermal methods $\left(200^{\circ} \mathrm{C}\right)$ as a pre-treatment. Data are representative of triplicate values with standard deviation shown. willow derived hydrolysates performed better than those from wheatstraw or miscanthus although this maybe an artefact related to these fractions containing $0.8 \mathrm{~g} / \mathrm{L}$ and $2 \mathrm{~g} / \mathrm{L}$ glucose (respectively) which may have provided an additional metabolic boost (Figs. 4B and 4C). However, the presence of the inhibitory compounds did reduce metabolic output of all hydrolysates when compared with controls (without the inhibitors present). When comparing hydrolysates derived from wheat-straw using the different pre-treatments, it was noted that in terms of metabolic output, yeast performed equally well in hydrolysates derived from either autohydrolytical or acid pre-treatment systems (Fig. 5A).

Autohydrolytical (aqueous-based hydrothermal) or steam explosion pre-treatment systems (autohydrolytical with an additional physical, decompressive effect) have been shown to liberate high concentrations of monomeric sugars from LCMs (Tomás-Pejó et al., 2008). However, use of relatively high temperatures has been shown to liberate high concentrations of certain inhibitory compounds (Tomás-Pejó et al., 2008). In this study, we observed lower concentrations of acetic acid in the hydrolysates derived from autohydrolytical pre-treatment when compared with the other pre-treatments employed. However, the hydrolysates produced using autohydrolytical methods did still contain significant concentrations of furfural. Hydrolysates derived from both autohydrolytical and acid pre-treatment methods were characterised by the presence of furfural (0.8-3.45 mM) and HMF (0.05-1.2 mM). Furfural and HMF have been shown to be derived from degradation of sugar molecules when under acid catalysed or high temperature hydrolysis (Taherzadeh and Karimi, 2008). Previous studies have demonstrated that $20 \mathrm{mM}$ furfural inhibits S. cerevisiae (Park et al., 2011; Greetham et al., 2014). This would suggest that the concentrations detected in these hydrolysates would not be significantly problematic for S. cerevisiae. However, the presence of furan compounds (such as furfural) is an unavoidable consequence of the use of relatively high temperatures $\left(>140^{\circ} \mathrm{C}\right)$ to break LCM into fermentable sugars (Tomás-Pejó et al., 2010). Additionally, the higher temperature steam explosion methods $\left(220^{\circ} \mathrm{C}\right)$ may generate up to $8 \mathrm{mM}$ furfural (Bailey et al., 2008). This can significantly reduce the ethanol yields achieved or reduce the volumetric productivity (the ethanol output per unit time) thus reducing the process efficiency.

3.6. Correlation of fermentation performance of hydrolysates (derived from acid pre-treatment of wheat-straw) with fermentations of control media with an equivalent carbon loading

The fermentation performance of S. cerevisiae NCYC2592 was evaluated using the pre-treatment generated hydrolysate. This hydrolysate containing pentose sugars and inhibitory compounds was derived from the acid pre-treatment of wheat-straw and supplemented with $4 \%$ glucose (included as a useable carbon source). This was then compared with the fermentation performance of the same yeast strain when using just YPD media (also containing 4\% glucose). The use of the acid pre-treatment paired with wheat-straw was chosen as the model system for further investigation due to a compromise between various factors and practical constraints. Wheat straw was chosen as the LCM biomass as use of this cereal straw has been highlighted as a potential energy crop within the UK with arable farmers actually willing to sell the crop for this purpose (Glithero, 2013a). The alkaline pre-treatment system was discounted as the hydrolysates exhibited poor fermentation performance. The autohydrolytical pre-treatment utilising the microwave reactor was highly effective, but only on a small scale (i.e., limited to a maximum initial working liquid phase volume of ca. $20 \mathrm{~mL}$, and with up to $50 \%$ of the initial liquid volume being absorbed by the biomass as the reactions proceed). Therefore, it was impractical for generating suitably large volumes $(0.1 \mathrm{~L})$ for larger trial fermentations to be conducted with adequate biological replication as the volume of recoverable hydrolysate was relatively low. Finally, the use of an acid catalysed hydrothermal pretreatment had the capacity for generating suitably large quantities of hydrolysate. Fermentation progression (of the larger scale system using the hydrolysate from wheat-straw with acid pre-treatment) was monitored by measuring weight loss over time, which has been shown to correlate with sugar utilisation (Powell et al., 2003). It was observed that fermentation profiles from the hydrolysates correlated well with 
fermentation profiles when using 4\% YPD as a control (Fig. 5B). However, during the initial stages of the fermentations, there was an approximate $2 \mathrm{~h}$ delay (extended yeast lag phase) between the test fermentation vessels (the pre-treatment derived hydrolysates) and the control fermentation vessels. However, even with the extended lag phase, all fermentations were still completed (attenuated) within $16 \mathrm{~h}$. Quantification of ethanol concentrations produced indicated there was a ca. $36 \%$ conversion of glucose into ethanol from the hydrolysates which compares with the $51 \%$ theoretical maximum for the stoichiometric conversion of glucose into ethanol. Hydrolysates derived from the acid pre-treatment of wheat-straw were shown to contain acetic acid and furfural as the principal inhibitory compounds (Figs. 2A and $2 B)$. Through the measurement of the effect of these inhibitors on yeast metabolic output, it was observed that acetic acid and furfural both individually reduced yeast metabolic output when compared with controls (Figs. 5C and 5D). Assays were all buffered to $\mathrm{pH} 5$ prior to the start to mimic conditions present at the beginning of fermentation (Verduyn et al. 1990). Therefore, external pH-derived effects could be discounted and the deleterious effects of the inhibitors confirmed.
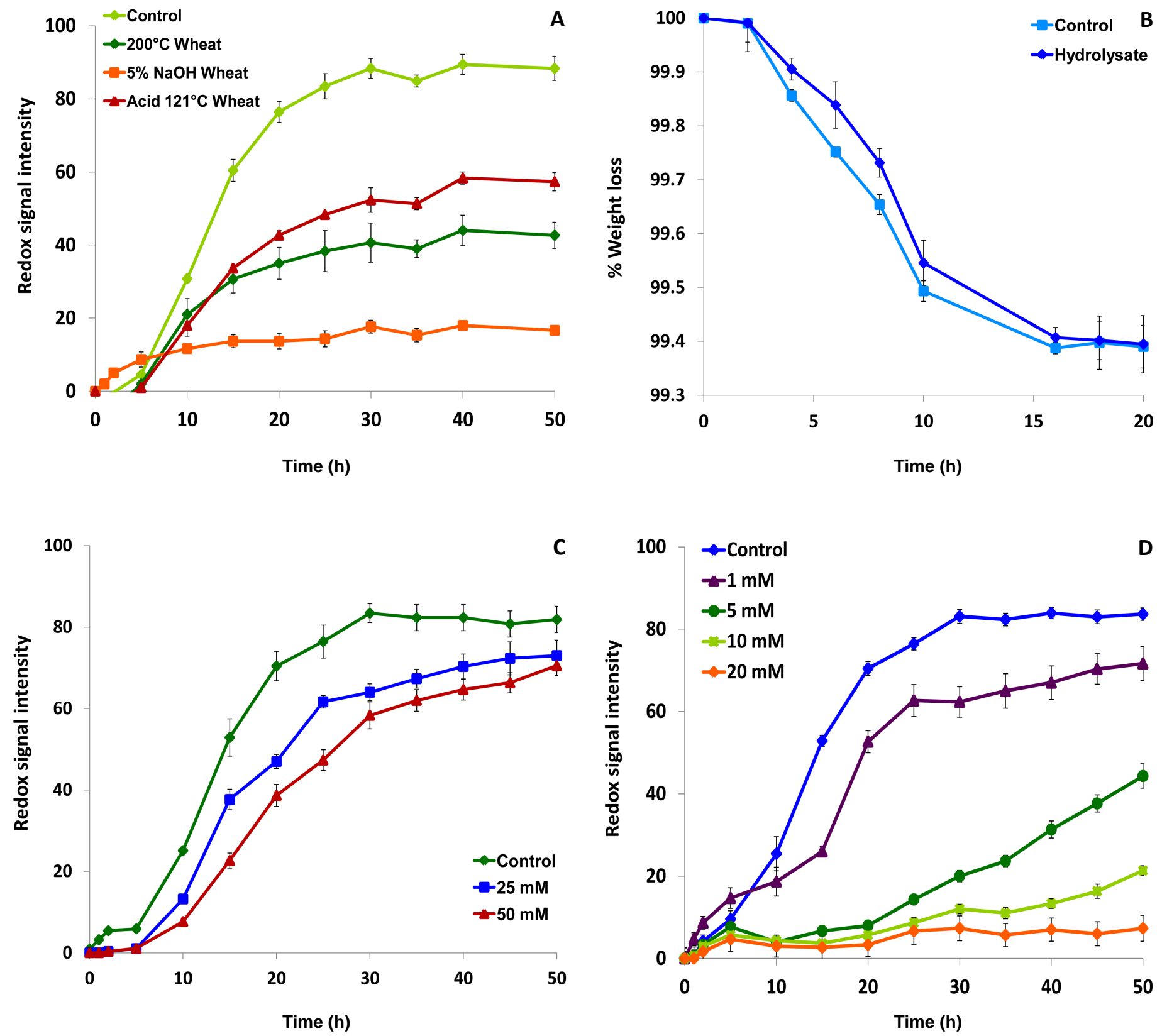

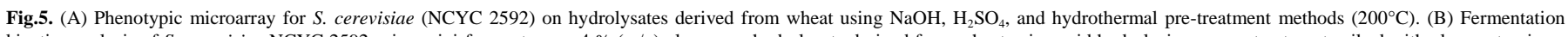
kinetics analysis of $S$. cerevisiae NCYC 2592 using mini-fermenters on $4 \%$ (w/v) glucose or hydrolysate derived from wheat using acid hydrolysis as a pre-treatment spiked with glucose to give a

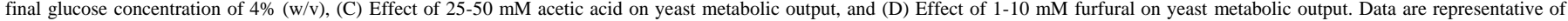
triplicate values with standard deviation shown. 


\section{Conclusions}

Acid pre-treatment $\left(1 \% \mathrm{H}_{2} \mathrm{SO}_{4}\right.$ at $\left.121^{\circ} \mathrm{C}\right)$ was concluded to be optimal system (in terms of sugar liberation, inhibitor generation, and fermentability) when compared to the alkaline $\left(5 \% \mathrm{NaOH}\right.$ at $\left.50^{\circ} \mathrm{C}\right)$ or autohydrolytical $\left(200^{\circ} \mathrm{C}\right)$ pre-treatment systems. Whilst alkaline pre-treatment was shown to enhance the enzymatic saccharification yields more than the other pretreatments (and also the generated hydrolysate had the lowest concentration of inhibitors present), the hydrolysate showed poor fermentability. The fermentability of the hydrolysates was determined using a phenotypic microarray (PM) to measure yeast metabolic activity. The PM provided a rapid, high-throughput screening tool to access fermentation performance and could be used to evaluate which pre-treatment systems where optimal for different lignocellulosic biomass.

\section{Acknowledgements}

The research reported here was supported (in full or in part) by the Biotechnology and Biological Sciences Research Council (BBSRC) Sustainable Bioenergy Centre (BSBEC), under the programme for 'Lignocellulosic Conversion to Ethanol' (LACE) [Grant Ref: $\mathrm{BB} / \mathrm{G} 01616 \mathrm{X} / 1]$. This is a large interdisciplinary programme and the views expressed in this paper are those of the authors alone, and do not necessarily reflect the views of the collaborators or the policies of the funding bodies. This project is in part financed by the European Regional Development Fund project EMX05568.

\section{References}

[1] Allen, S.A., Clark, W., McCaffery, J.M., Cai, Z., Lanctot, A., Slininger, P.J., Liu, Z.L., Gorsich, S.W., 2010. Furfural induces reactive oxygen species accumulation and cellular damage in Saccharomyces cerevisiae. Biotechnol. Biofuels. 3(2), 1-10.

[2] Almeida, J.R., Modig, T., Petersson, A., Hähn-Hägerdal, B., Lidén, G., Gorwa-Grauslund, M.F., 2007. Increased tolerance and conversion of inhibitors in lignocellulosic hydrolysates by Saccharomyces cerevisiae. J. Chem. Technol. Biotechnol. 82(4), 340-349.

[3] Antoni, D., Zverlov, V.V., Schwarz, W.H., 2007. Biofuels from microbes. Appl. Microbiol. Biotechnol.77(1), 23-35.

[4] Bailey, A.M., Paulsen, I.T., Piddock, L.J., 2008. RamA confers multidrug resistance in Salmonella enterica via increased expression of acrB, which is inhibited by chlorpromazine. Antimicrob. Agents Chemother. 52(10), 3604-3611.

[5] Balat, M., 2011. Production of bioethanol from lignocellulosic materials via the biochemical pathway: a review. Energy Convers. Manage. 52(2), 858-875.

[6] Banerjee, G., Car, S., Scott-Craig, J.S., Hodge, D.B., Walton, J.D., 2011. Alkaline peroxide pretreatment of corn stover: effects of biomass, peroxide, and enzyme loading and composition on yields of glucose and xylose. Biotechnol. Biofuels. 4(1), 16.

[7] Bauen, A.W., Dunnett, A.J., Richter, G.M., Dailey, A.G., Aylott, M., Casella, E., Taylor, G., 2010. Modelling supply and demand of bioenergy from short rotation coppice and Miscanthus in the UK. Bioresour. Technol. 101(21), 8132-8143.

[8] Binod, P., Satyanagalakshmi, K., Sindhu, R., Janu, K.U., Sukumaran, R.K., Pandey, A., 2012. Short duration microwave assisted pretreatment enhances the enzymatic saccharification and fermentable sugar yield from sugarcane bagasse. J. Renew. Energ. 37(1), 109-116.

[9] Carvalheiro, F., Duarte, L.C., Girio, F.M., 2008. Hemicellulose biorefineries: a review on biomass pretreatments. J. Sci. Ind. Res. 67(11), 849-864.

[10] Chandra, R.P., Bura, R., Mabee, W.E., Berlin, A., Pan, X., Saddler, J.N., 2007. Substrate pretreatment: the key to effective enzymatic hydrolysis of lignocellulosics? Adv. Biochem. Eng. Biotechnol. 108, 67-93.

[11] Chang, V.S., Holtzapple, M.T., 2000. Fundamental factors affecting biomass enzymatic reactivity. in: Biotechnology for Fuels and Chemicals. Humana Press. pp. 5-37.

[12] Chheda, J.N., Román-Leshkov, Y., Dumesic, J.A., 2007. Production of 5-hydroxymethylfurfural and furfural by dehydration of biomassderived mono-and poly-saccharides. Green Chem. 9(4), 342-350.
[13] Chundawat, S.P., Beckham, G.T., Himmel, M.E., Dale, B.E., 2011a. Deconstruction of lignocellulosic biomass to fuels and chemicals Annu. Rev. Chem. Biomol. Eng. 2, 121-145.

[14] Chundawat, S.P., Bellesia, G., Uppugundla, N., da Costa Sousa, L., Gao, D., Cheh, A.M., Agarwal, U.P., Bianchetti, C.M., Phillips Jr, G.N., Langan, P., 2011b. Restructuring the crystalline cellulose hydrogen bond network enhances its depolymerization rate. J. Chem. Soc. 133(29), 11163-11174.

[15] Coote, N., Kirsop, B., 1976. Factors responsible for the decrease in pH during beer fermentations. J. Inst. Brew. 82(3), 149-153.

[16] DEFRA, 2007. PLanting and growing miscanthus- natural England Best Practice Guidelines.

[17] Eggeman, T., Elander, R.T., 2005. Process and economic analysis of pretreatment technologies. Bioresour. Technol. 96(18), 2019-2025.

[18] Galbe, M.Z., Zacchi, G., 2012. Pretreatment: The key to efficient utilization of lignocellulosic materials. Biomass Bioenergy. 46, 7078

[19] Ghose, T., 1987. Measurement of cellulase activities. Pure Appl. Chem. 59(2), 257-268

[20] Girio, F.M., Fonseca, C., Carvalheiro, F., Duarte, L.C., Marques, S. Bogel-Lukasik, R., 2010. Hemicelluloses for fuel ethanol: a review. Bioresour. Technol. 101(13), 4775-4800.

[21] Glithero, N., Ramsden, S.J., Wilson P., 2013a. Barriers and incentives to the production of bioethanol from cereal straw: a farm business perspective. Energ. Policy. 59, 161-171.

[22] Glithero, N.J., Wilson, P., Ramsden, S.J., 2013b. Prospects for arable farm uptake of Short Rotation Coppice willow and miscanthus in England. Appl. Energy. 107(100), 209-218.

[23] Greetham, D., 2014. Phenotype microarray technology and its application in industrial biotechnology. Biotechnol. Lett. 36(6), 1153-1160

[24] Greetham, D., Wimalasena, T., Kerruish, D., Brindley, S., Ibbett, R. Linforth, R., Tucker, G., Phister, T., Smart, K., 2014. Developmen of a phenotypic assay for characterisation of ethanologenic yeast strain sensitivity to inhibitors released from lignocellulosic feedstocks. J. Ind. Microbiol. Biotechnol. 41(6), 931-945.

[25] Hawkins, G.M., Doran-Peterson, J., 2011. A strain of Saccharomyces cerevisiae evolved for fermentation of lignocellulosic biomass displays improved growth and fermentative ability in high solids concentrations and in the presence of inhibitory compounds. Biotechnol. Biofuels. 4(1), 1-14.

[26] Jorgensen, U., 2011. Benefits versus risks of growing biofuel crops: the case of Miscanthus. Curr. Opin. Environ. Sustain. 3(1), 24-30.

[27] Klinke, H.B., Thomsen, A., Ahring, B.K., 2004. Inhibition of ethanol-producing yeast and bacteria by degradation products produced during pre-treatment of biomass. Appl. Microbiol. Biotechnol. 66(1), 10-26.

[28] McKendry, P., 2002. Energy production from biomass (Part 1) Overview of biomass. Bioresour. Technol. 83(1), 37-46.

[29] Mira, N.P., Teixeira, M.C., Sá-Correia, I., 2010. Adaptive response and tolerance to weak acids in Saccharomyces cerevisiae: a genomewide view. OMICS. 14(5), 525-540.

[30] Narendranath, N., Thomas, K., Ingledew, W., 2001. Effects of acetic acid and lactic acid on the growth of Saccharomyces cerevisiae in a minimal medium. J. Ind. Microbiol. Biotechnol. 26(3), 171-177.

[31] Nguyen, Q.A., Tucker, M.P., Keller, F.A., Eddy, F.P., 2000. Twostage dilute-acid pretreatment of softwoods. In: Twenty-first Symposium on biotechnology for fuels and chemicals. Humana Press. pp. 561-576.

[32] Palmqvist, E., Galbe, M., Hahn-Hagerdal, B., 1998. Evaluation of cell recycling in continuous fermentation of enzymatic hydrolysates of spruce with Saccharomyces cerevisiae and on-line monitoring of glucose and ethanol. Appl. Microbiol. Biotechnol. 50(5), 545-551.

[33] Park, S.E., Koo, H.M., Park, Y.K., Park, S.M., Park, J.C., Lee, O.K. Park, Y.C., Seo, J.H., 2011. Expression of aldehyde dehydrogenase 6 reduces inhibitory effect of furan derivatives on cell growth and ethanol production in Saccharomyces cerevisiae. Bioresour. Technol. 102(10), 6033-6038.

[34] Powell, C.D., Quain, D.E., Smart, K.A., 2003. The impact of brewing yeast cell age on fermentation performance, attenuation and flocculation. FEMS Yeast Res. 3(2), 149-157. 
[35] Rathmann R., Szklo, A., Schaeffer R., 2010. Land use competition for production of food and liquid biofuels: an analysis of the arguments in the current debate. Renew. Energ. 35(1), 14-22.

[36] Ray, M.J., Brereton, N.J.B., Shield, I., Karp, A., Murphy R.J., 2012. Variation in Cell Wall Composition and Accessibility in Relation to Biofuel Potential of Short Rotation Coppice Willows. Bioenerg. Res. 5, 685-698.

[37] Saha, B.C., Cotta, M.A., 2006. Ethanol production from alkaline peroxide pretreated enzymatically saccharified wheat straw. Biotechnol. Progr. 22(2), 449-453.

[38] Sticklen, M.B., 2008. Plant genetic engineering for biofuel production: towards affordable cellulosic ethanol. Nat. Rev. Genet. 9(6), 433-443.

[39] Taherzadeh, M.J., Karimi, K., 2008. Pretreatment of Lignocellulosic Wastes to Improve Ethanol and Biogas Production: a Review. Int. J. Mol. Sci. 9(9), 1621-1651.

[40] Tomás-Pejó, E., Ballesteros, M., Oliva, J., Olsson, L., 2010. Adaptation of the xylose fermenting yeast Saccharomyces cerevisiae F12 for improving ethanol production in different fed-batch SSF processes. J. Ind. Microbiol. Biotechnol. 37(11), 1211-1220.
[41] Tomás-Pejó, E., Oliva, J.M., Ballesteros, M., Olsson, L., 2008 Comparison of SHF and SSF processes from steam-exploded wheat straw for ethanol production by xylose-fermenting and robust glucose-fermenting Saccharomyces cerevisiae strains. Biotechnol. Bioeng. 100(6), 1122-1131.

[42] Verduyn, C., Postma, E., Scheffers, W.A., Van Dijken, J., 1990. Energetics of Saccharomyces cerevisiae in anaerobic glucoselimited chemostat cultures. J. Gen. Microbiol. 136(3), 405-412.

[43] Wimalasena, T.T., Greetham, D., Marvin, M.E., Liti, G., Chandelia Y., Hart, A., Louis, E.J., Phister, T.G., Tucker, G.A., Smart, K.A. 2014. Phenotypic characterisation of Saccharomyces spp. yeast for tolerance to stresses encountered during fermentation of lignocellulosic residues to produce bioethanol. Microb. Cell Fact. 13(1), 47.

[44] Yang, B., Wyman, C.E., 2008. Characterization of the degree of polymerization of xylooligomers produced by flowthrough hydrolysis of pure xylan and corn stover with water. Bioresour. Technol. 99(13), 5756-5762.

[45] Zhu, L., O’Dwyer, J.P., Chang, V.S., Granda, C.B., Holtzapple, M.T., 2008. Structural features affecting biomass enzymatic digestibility. Bioresour. Technol. 99(9), 3817-3828. 